The conclusion come to from the consideration of all the observations is that the dust in the atmosphere begins to condense vapour long before the air is cooled to the dew-point. It seems probable that in all states of humidity the dust has some moisture attached to it, and that, as the humidity increases, the load of moisture increases with it.

Another method of testing the condensing power of dust for water-vapour is then described. In working this method the dust is collected on a glass mirror, and its condensing power is determined by placing the mirror over a cell in which water is circulated, in the manner of a Dines hygrometer. The temperature at which condensation takes place on the dust and on a cleaned part of the glass is observed. The difference in the two readings gives the condensing power of the dust. One kind of dust artificially prepared was found to condense vapour just at the dew-point, while another condensed it at a temperature $17^{\circ}$ above the saturation-point. The atmospheric dust was collected on the mirrors on the same principle as that used in the thermic filter described by the author in a previous paper, the dust being deposited by difference of temperature, the necessary heat being obtained by fixing the collecting mirrors on a windowpane. Dust was also collected by allowing it to settle on the plates. The atmospheric dust was found to condense vapour at temperatures varying from $\mathrm{I}^{\mathrm{c}} \cdot 8$ to $4^{\mathrm{c}} \cdot 5$ above the dew-point. This condensing power of dust explains why glass such as that in windows, picture frames, \&c., often looks damp while the air is not saturated; and in part it explains why it is so necessary to keep electrical apparatus free from dust, if we wish to have good insulation.

The constitution of haze is then considered. It is shown that in many cases it is simply dust, on which there seems to be always more or less moisture. But as what is known as haze is generally seen in dry air, the effect is principally due to dust.

Some notes from the Rigi Kulm are given, where "glories" and coloured clouds were seen. The condition of the transparency of the lower air as seen from the top of the mountain is discusse 1 with the aid of the observations made by observers at the lower levels. These observations were kindly suppiied by M. Bilwiller, of the Swiss Meteorological Office. The difference observed at the top of the mountain in the transparency of the air in different directions is shown to have been caused by a difference in the humidity of the air in the different directions. The variation in the number of particles on the top of the mountain is considered, and it is shown that the great increase in the number which took place on the second day was probably due to the valley air being driven up the slopes, reasons being given for this supposition. The colouring in clouds, and on scenery at sunrise and sunset, as seen from the tops of mountains and valleys, is remarked upon, and it is shown that there is reason for supposing that when seen from the lower level the colours will generally be the more brilliant and varied.

The relation of the amount of dust to the barometric distribution is then investigated-as to whether cyclonic or anticyclonic areas have most dust in them. It is shown that there is most dust in the anticyclonic areas. The interpretation of this, however, is shown to be that the amount of dust depends on the amount of wind at the time, and as there is generally little wind in anticyclonic areas, there is generally much dust. Diagrams are given showing by means of curves the amount of dust on each day, and also the velocity of the wind. The curves are found to bear a close relation to each other-when the one rises the other falls. The only exceptions to this are when the stations where the observations were made are not equally surrounded in all directions by sources of pollution. In that case, even with little wind, if it blows from an unpolluted direction the amount of dust is not great.
The increase in the dust particles which takes place when the wind falls, seems to point to a probable increase of the infection germs in the atmosphere when the weather is calm. As, however, the conditions are not quite the same, the organic germs being much larger than most of the dust particles, and settling more quickly, it may be as well, while accepting the suggestion, to refrain from drawing any conclusion.

In all the fogs tested, the amount of dust has been found to be great. This is shown to be what might now be expected from a consideration of the conditions under which fogs are formed. One condition necessary for the formation of a fog is that the air be calm. But when the air is calm both dust and moisture tend to accumulate, and the dust, by increasing the radiating power of the air, soon lowers its temperature and causes it to condense vapour on the dust and form a fog. The thickness of a fog seems to depend in part on the amount of dust present, as town fogs, apart from their greater blackness, are also more dense than country ones. The greater amount of dust in city air, by increasing its radiating power, it is thought, may be the cause of the greater frequency of fogs in town than in country air.

At the end of the paper some relations are pointed out between the amount of dust and the temperature at the time the observations were made, showing that when there was a large amount of dust there was also a high temperature; and some speculations are entered into as to the effect of dust on climate. But it is at the same time pointed out that the observations are far too few and imperfect to form a foundation for any important conclusi $n$ on that subject.

In a short appendix is given the result of some tests made between January 23 and 29 of this year at Garelochead. During the gale on Saturday, the $25 \mathrm{th}$, the number was rather under Iooo per cubic centimetre. On Monday, though the wind was still high, the number fell to about 250 ; and on Tuesday, when the wind had fallen and veered to the north, the number fell lower than had been previously observed. The number varied from a little over 100 to about 90 per cubic centimetre. On this day the air was remarkable for its clearness, the sun was very strong, and the evening set in with a sharp frost.

\section{JOHN AITKEN.}

P.S.--The author of the paper also showed at the same meeting of the Society the apparatus which have just been constructed from his designs for the Observatory on Ben Nevis. The apparatus has been constructed by the aid of a Government grant, obtained by the Council of the Scottish Meteorological Society, for the purpose of carrying on the investigation on the dust in the atmosphere at the top of Ben Nevis. Two complete sets of apparatus were shown. The one is the large laboratory form of the dust-counter, and is to be fixed, in the meantime, in the tower of the Observatory ; the air being taken in to it by means of a pipe. The other is the small portable form of instrument, to be used when the direction of the wind is such as to bring the smoke of the Observatory towards the tower. This latter instrument has for a short time been in the hands of Mr. Rankin, one of the Ben Nevis observers, who has been practising with it near Edinburgh before beginning regular work at the Observatory.

\section{A UNIFORM SYSTEM OF RUSSIAN TRANSLITERATION.}

$\mathrm{U} \mathrm{P}$ to the present time no one system of transliterating Russian names and titles into English has been generally adopted. Some of those most interested in the cataloguing and recording of Russian scientific literature have therefore arranged the following scheme in order to secure the general use of a system which will enable 
those unacquainted with Russian, not only to transliterate from that language into English, but also to recover the original Russian spelling, and so to trace the words in a dictionary.

\section{RUSSIAN-ENGLISH.}

\begin{tabular}{|c|c|c|c|c|c|}
\hline 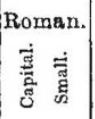 & 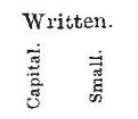 & 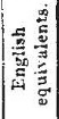 & 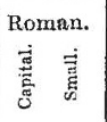 & 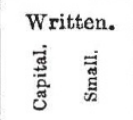 & 总 \\
\hline 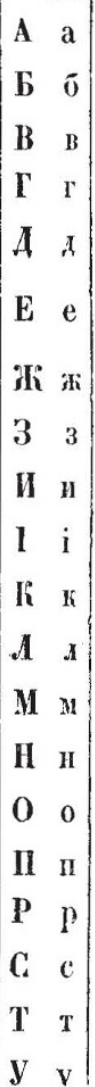 & 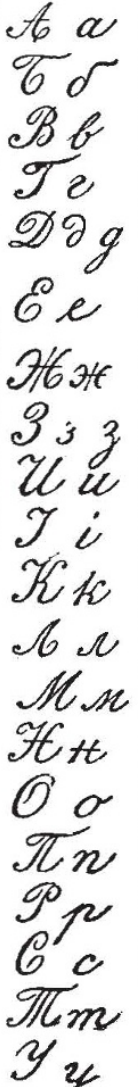 & $\begin{array}{c}z h \\
z \\
i \\
i \\
h \\
l \\
m \\
n \\
0 \\
p^{p} \\
r \\
s \\
t \\
u\end{array}$ & 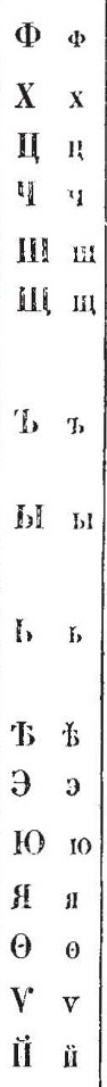 & 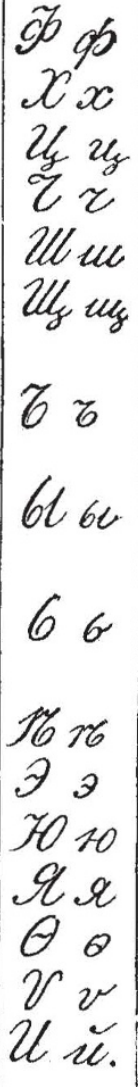 & 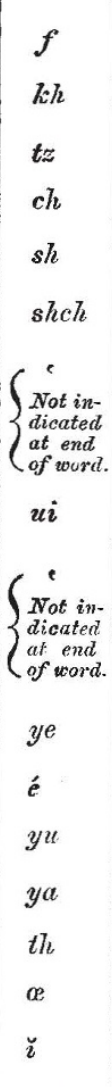 \\
\hline
\end{tabular}

ENGLISH-RUSSIAN.

\begin{tabular}{|c|c|c|c|c|c|c|c|}
\hline$a$ & A & $\bar{\imath}$ & II & $p$ & II & $u i$ & LI \\
\hline$b$ & b & $\check{i}$ & İ & $r$ & $P$ & $v$ & $B$ \\
\hline$c h$ & I & $k$ & K & $s$ & C & $y e$ & II \\
\hline$d$ & A & $k h$ & $\mathbf{X}$ & $s h$ & III & $y_{0}$ & $\mathrm{~J}$ \\
\hline$e$ & $\mathrm{E}$ & $l$ & I & shch & III & $y u$ & 10 \\
\hline$\dot{e}$ & $\ni$ & $m$ & II & $t$ & $\mathrm{~T}$ & & 3 \\
\hline$f$ & $\Phi$ & $n$ & $\mathrm{H}$ & $t h$ & $\Theta$ & $z h$ & ili \\
\hline$g h$ & $\Gamma$ & $o$ & 0 & $t$ & Ц & c & $\mathrm{b}$ \\
\hline$i$ & I & $\propto$ & $r$ & $u$ & $\mathbf{y}$ & e & b \\
\hline
\end{tabular}

With reference to some of the letters a few words of explanation are necessary.

$g h$ is adopted in preference to $g$ for $\mathrm{r}$, since this letter is also the equivalent of $h$ in such words as Ги spa, which, if transliterated gidra, would lose its resemblance to the word hydra, with which it is identical.

Although $\mathbf{i}$ and $\boldsymbol{H}$ have the same sound, and with a few rare exceptions the letter used in the original may be recognized by a simple rule, it is recommended that the latter should be distinguished by the sign - , since the use of the same English symbol for two Russian characters is objectionable.

The semi-vowels, $\mathrm{b}$ and $\mathrm{b}$, must be indicated when present, except at the end of a word, by the sign " placed above the line; otherwise, the transliteration of two Russian characters might give the same sequence as one of the compound equivalents, and it would become difficult to trace the words in a dictionary.

As regards the compound equivalents, nine out of the twelve may be at once recognized, since $h$ must always be coupled with the preceding, and $y$ with the succeeding, letter.

Where proper names have been Russianized, it is better whenever possible to use them in the original form rather than to re-transliterate them; there is no reason why Wales should be rendered $\mathrm{Uel}^{i}$ s, or Wight written as Uait. When a Russiain name has a more familiar transliterated form, it is advisable to quote this as well as an exact transliteration with a cross reference.

The system will be adopted without delay in the following publications: the Catalogue of the Natural History Museum Library; the Zoological and Geological Records; the publications of the Royal Society, the Linnean, Zoo logical, and Agricultural Societies, and the Institution of Civil Engineers; the Mineralogical Magazine, and the Annals of Botany ; and it is hoped that the system will be generally used.

An expression of grateful thanks is due to those who have assisted in the arrangement of this system by criticisms and suggestions; more especially to Madame de Novikoff and N. W. Tchakowsky.

The undersigned either accept the proposed system in the publications with which they are severally connected, or express their approval of the same :-

W. H. Flower, C.B. ... Director, Natural History Museum. W. R. Morfill ... ... Reader in Russian, \&sc., Oxford.

F. Löwinson-Lessing $\ldots$ University, St. Petersburg.

S. H. Scudder $\quad \ldots \quad \ldots \quad$ U.S. Geological Survey.

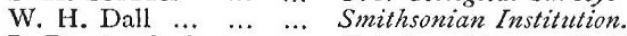

B. Daydon Jackson $\quad \ldots$. Bot. Sec., Linnean Society.

P. L. Sclater .. $\quad \ldots \quad \ldots \quad$ Zoological Society.

F. E. Beridard $\ldots . . \ldots$ Zoological Record.

W. Topley $\quad \ldots \quad \ldots \quad \ldots$ G Gological Record.

C. Davies Sherborn $\ldots\}$ Geological Rccord.

$\left.\begin{array}{lll}\text { I. Bayley Balfour } & \ldots & \ldots \\ \text { S. H. Vines } & \ldots & \ldots\end{array}\right\}$ Annals of Botany.

H. A. Miers ...

J. T. Naaké. ...

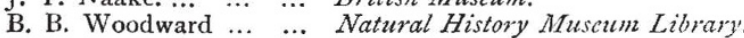

J. W. Gregory $\quad \ldots \quad \ldots \quad$ Natural History Muscum.

THE BOTANICAL INSTITUTE AND MARINE STATION AT KIEL.

PROF. J. REINKE contributes to the Botanisches Centralblatt a very interesting account of the Botanical Institute at Kiel, and of the Marine Station attached to it, as far as they are employed for botanical researches.

The harbour of Kiel is remarkably favourable for the observation of marine Algæ and the investigation of their life-history. In brown seaweeds the immediate neighbourhord is exceedingly rich, being scarcely inferior in the number of species to any other spot on the coasts of Europe. One important order, the Dictyotaceæ, is 